\title{
Effect of Speed on Friction and Wear Properties of Cu-based Material
}

\author{
Wen Pei a ${ }^{a}$ Zhenxin Duan ${ }^{b}$, Xuebo Gong ${ }^{c}$, Jing Zeng ${ }^{d}$ and Hua Chen ${ }^{e, *}$ \\ School of Material Science and Engineering, Changchun University of Technology, Changchun \\ 130000, China. \\ a532119494@qq.com, b1737696433@qq.com, c178157717@qq.com, echenhua@ccut.edu.cn \\ Corresponding author: Hua Chen
}

Keywords: powder metallurgy, Cu-based friction material, friction and wear, friction coefficient.

\begin{abstract}
According to the performance requirements of brake friction plate in the high speed train, $\mathrm{Cu}$-based friction material was prepared by powder metallurgy technology. The friction components are mainly atomized $\mathrm{Fe}$, a small amount of $\mathrm{Cr}$ and $\mathrm{SiO} 2$. And a high coefficient is caused by the friction resistance of these particles in the friction surface. The graphite forms a layer of solid lubricating film on the friction surface to ensure a stable friction coefficient under the all kinds of friction conditions. The compressive strength of sintered samples were tested by DDL50 Electronic Universal Testing Machine, and the property of dry friction and wear were tested by vertical universal friction-wear testing machine. The wearing morphologies were observed by SEM and the effects of friction speed on wear rate and friction coefficient were analyzed. The result shows that $\mathrm{Cu}$-based containing larger natural flake graphite and smaller Fe particles has good friction wear performance. And when the load varying from $50 \mathrm{~N}$ to $150 \mathrm{~N}$ at the speed of $600 \mathrm{r} / \mathrm{min}$, the friction coefficient is about $0.4 \sim 0.48$, the coefficient varies little and is very stable. The main wear mechanisms are abrasive wear and oxidation wear.
\end{abstract}

\section{Introduction}

With the rapid development of high speed railway, higher requirements for the performance of brake pads are put forward, which including the appropriate friction coefficient, good wear resistance, and a certain stability under high speed and high load [1-3]. Cu-based powder metallurgy material is applied to the brake material of high speed train for its stable friction coefficient and good wear resistance. This friction material is based on copper, adding graphite, $\mathrm{SiO}_{2}$ and other non-metallic components and prepared by powder metallurgy, so that it has a good friction and wear properties [4, 5]. At present, the trains emergency braking mainly depends on the friction between the brake disc in vehicle brake system and the friction pair of brake pad, which requires the brake pads to be stable at different velocities. Therefore, the study of the friction and wear properties will provide theoretical basis of brake products performance control.

$\mathrm{Xu}[6]$ et al studied on friction and wear properties of $\mathrm{C} / \mathrm{C}$ composites, results show that the friction coefficient increases first and then decreases with the increase of friction speed, while the wear rate increases all. The research of R. Holinski [7] shows that the surface temperature plays an important role in the process of friction and wear of the metal matrix composites. The temperature increases with the increase of friction speed which leads to the softening of the matrix material, the decrease of the strength and easy to form oxide film which is beneficial to reduce friction coefficient. Han [8] prepared the $\mathrm{Cu}-\mathrm{C}-\mathrm{SiO}_{2}$ sintered material by powder metallurgy technique to study the relationship between the friction speed, third body and friction and wear properties. The results show that with the increase of the friction speed the third body of the friction surface changes from granular to dense, the surface micro-hardness increases and the friction coefficient decreases.

Graphites often added to the material as a kind of lubricating component, but the graphite and $\mathrm{Cu}$ based are insoluble and the wettability is poor. The usual addition of small pieces of graphite will reduce the continuity of the material and resulting in increased porosity of the material. Therefore, the larger natural flake graphites $(150 \sim 250 \mu \mathrm{m})$ and smaller iron particles $(\leq 70 \mu \mathrm{m})$ were selected in 
this experiment which will greatly improve the compactness of the material and increase the friction coefficient.

The strength of iron is higher than that of copper and it has good wettability with copper. Iron is often added as a strengthening component for the $\mathrm{Cu}$-based materials. Usually used iron powders $(74 \mu \mathrm{m})$ can not be well integrated into the material because of larger particles when it is sintering. And it will cause massive spalling in the course of friction and exacerbates the wear. Therefore, atomized iron $(37 \mu \mathrm{m})$ was used in this experiment to avoid this problem. The atomized iron would uniformly disperse in the matrix during sintering and enhanced the matrix phase.

In this study, $\mathrm{Cu}$ was selected as matrix, $\mathrm{Sn}$ and $\mathrm{Fe}$ were added as strengthening components, graphite as lubricant component, $\mathrm{SiO}_{2}$ as the friction component and added a small amount of $\mathrm{Cr}$ to reduce the adhesion with the dual. The micro-morphology before and after wearing test and the effects of friction speed on wear rate and friction coefficient were studied.

\section{Experimental materials and methods}

The raw materials used in the experiment are electrolytic copper powders, natural flake graphite $(150 \sim 250 \mu \mathrm{m})$, tin, iron, chromium and $\mathrm{SiO}_{2}$. The raw powders purity and particle size as shown in Table 1. The compositions of the experimental material are Fe-20wt.\%, graphite-10wt.\%, Sn-5wt.\%, $\mathrm{Cr}-4 \mathrm{wt} . \%, \mathrm{SiO}_{2}-1.5 \mathrm{wt} . \%$ and the remaining is copper. These raw powders were mixed at the speed of $200 \mathrm{r} / \mathrm{min}$ for $20 \mathrm{~min}$ by ball mill. The mixed powder was cold pressed under a pressure of $600 \mathrm{MPa}$ and sintered in a hydrogen atmosphere at a temperature of $830 \pm 10^{\circ} \mathrm{C}$ for $1.5 \mathrm{~h}$. The density of the sintered sample is $5.832 \mathrm{~g} / \mathrm{cm}^{3}$, the relative density is $75.4 \%$ and the hardness is $119 \mathrm{HRB}$.

Table 1 Purity and particle size parameters of raw material powders

\begin{tabular}{|c|c|c|}
\hline Raw material & Purity $(\%)$ & Particle size $(\mu \mathrm{m})$ \\
\hline $\mathrm{Cu}$ & $\geq 98.5$ & $\leq 50$ \\
\hline $\mathrm{Graphite}$ & $\geq 99.0$ & $150 \sim 250$ \\
\hline $\mathrm{Sn}$ & $\geq 98.5$ & $\leq 75$ \\
\hline $\mathrm{Fe}$ & $\geq 99.0$ & $\leq 70$ \\
\hline $\mathrm{Cr}$ & $\geq 99.5$ & $\leq 20$ \\
\hline $\mathrm{SiO}_{2}$ & $\geq 98.5$ & $\leq 15$ \\
\hline
\end{tabular}

The compressive strength was measured by the DDL50 Electronic Universal Testing Machine. The size of the compressed specimen was $\Phi 5 \times 12 \mathrm{~mm}$. The vertical universal friction-wear testing machine was used to do the dry friction and wear tests. The material of friction pair is heat-treated 45 steel with a hardness of 42HRC. The friction speeds are $200 \mathrm{r} / \mathrm{min}, 400 \mathrm{r} / \mathrm{min}$ and $600 \mathrm{r} / \mathrm{min}$ and the friction time is $10 \mathrm{~min}$. The loads are $50 \mathrm{~N}, 75 \mathrm{~N}, 100 \mathrm{~N}$ and $150 \mathrm{~N}$.

\section{Experimental results and analysis}

\subsection{Micro-morphology of sintered microstructure.}

Fig. 1 shows that the gray matrix is $\mathrm{Cu}-\mathrm{Sn}$ solid solution $(\alpha-\mathrm{Cu})$. The black graphites are perpendicular to the direction of the pressure. The gray Fe particles are homogeneous distributed in the $\mathrm{Cu}-\mathrm{Sn}$ matrix in a free state. The hardness of Fe particles is higher than that of $\mathrm{Cu}$ but lower than $\mathrm{SiO}_{2}$ particles, so iron can improve the strength of the $\mathrm{Cu}$-base and make relatively small damage to the friction pair. The fine $\mathrm{SiO}_{2}$ particles can significantly enhance the friction coefficient. The role of $\mathrm{Cr}$ and $\mathrm{Fe}$ is similar that is improve the resistance friction and wear properties of the matrix.

The X-ray diffraction results of the sample is shown in Fig. 2. It can be seen that the diffraction peaks of $\mathrm{Cu}$ shows a certain deviation. The reason is $\mathrm{Sn}$ solid solute in $\mathrm{Cu}$ and lead to lattice distortion. Graphite and Fe cannot react chemically with other components. 

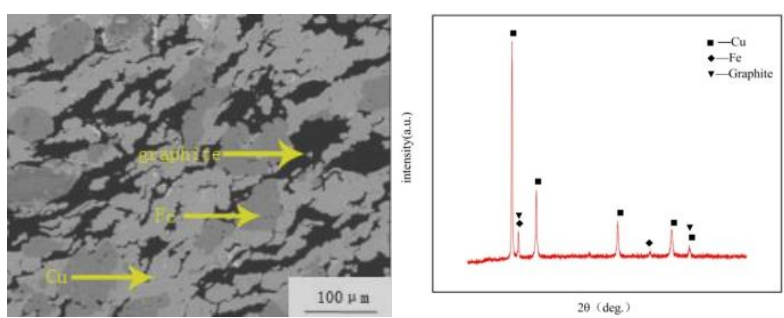

Fig. 1 SEM Micro-morphology Fig. 2 XRD Pattern

\subsection{Density and compressive strength.}

Table 2 shows the test density, theoretical density, relative density, porosity and hardness of the experimental material. The density of the friction material has an important influence on the hardness, strength and the friction and wear properties. The too low density will lead to weaken of grainboundaries strength, and can not ensure the friction wear performance requirement of material under certain pressure. Therefore, the friction material require opportune density and strength.

In the experimental material, the hardness of graphite and $\mathrm{Cu}$ is very low, but the hardness of $\mathrm{Fe}$, $\mathrm{Cr}$ and $\mathrm{SiO} 2$ are relatively higher. When they were added to the $\mathrm{Cu}$-based, the expansion of the crack and internal strain zone were obstructed, thus the hardness, the strength and the plastic deformation resistance of the material were improved. At the same time, this kind of friction material with soft and hard phase grains shows better wear resistance in the wearing process. However, higher density and hardness will reduce the lubrication effect of graphite, damage to the friction pair and even bring about serious noise pollution. Moreover, it would also lead to unstable friction coefficient when the hard particles fall off.

Fig. 3 is the true stress-true strain curve of the compression test. The flow stress increases rapidly with the increase of true strain at the initial stage of compressive deformation. When the true strain is about 0.15 , the true stress reaches its peak value. Subsequently, as the true strain continues to increase, the sample gradually cracks and finally breaks. Its compressive strength reaches $78.77 \mathrm{MPa}$. This value meets the performance requirements of friction brake-block in high speed train [9].

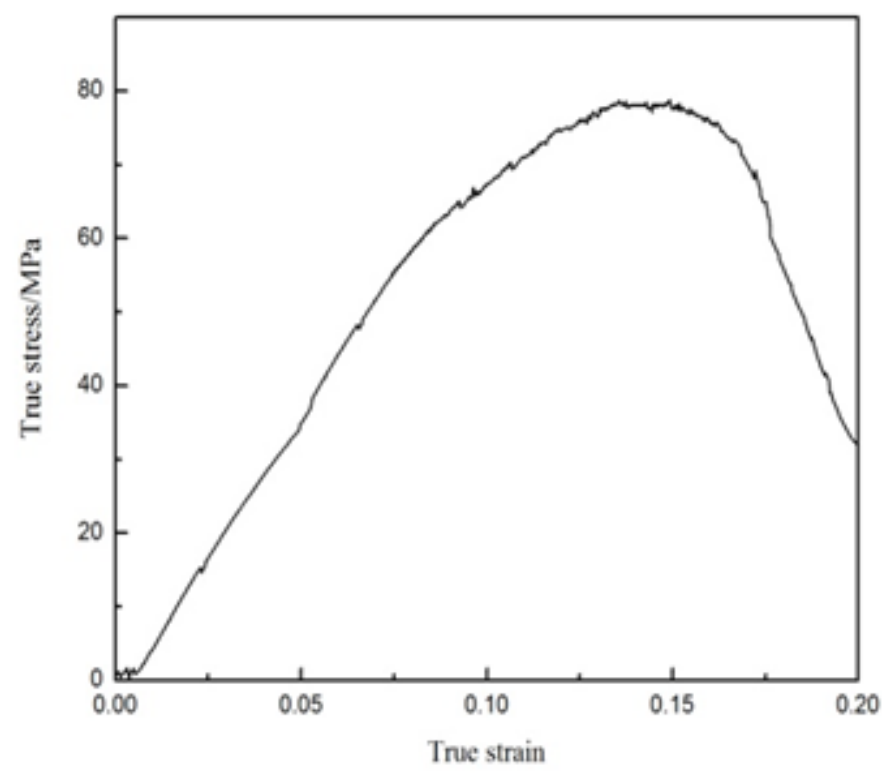

Fig. 3 The curve of true stress-true strain

\subsection{Effect of load on friction coefficient.}

Fig. 4 shows the friction coefficient curves of $200 \mathrm{r} / \mathrm{min}, 400 \mathrm{r} / \mathrm{min}$ and $600 \mathrm{r} / \mathrm{min}$ under the load of $50 \mathrm{~N}, 75 \mathrm{~N}, 100 \mathrm{~N}$ and $150 \mathrm{~N}$.The surface temperature of material increases with the wear time increasing, so the strength of the matrix decreases. The mechanical mixing layer on the surface falls off, resulting in the new surface is exposed and the friction coefficient increases. Then a new mixed mechanical layer is formed on the exposed new surface. As shown in the Fig. 4(c), (d), the friction coefficient of the material is stable when the newly formed mechanical layer is equal to the speed of 
shedding. The friction coefficient is the largest at 200r/min. The friction coefficients at steady are $0.58,0.59,0.6$ and 0.62 under $50 \mathrm{~N}, 75 \mathrm{~N}, 100 \mathrm{~N}$ and $150 \mathrm{~N}$. The greater the applied load when friction, the greater the magnitude of the bite between the frictional contact surfaces. Therefore, the friction coefficient becomes larger.

The effect of the braking speed on the friction coefficient is indirectly reflected by the high temperature yield strength of the material. In the high-speed friction process, kinetic energy will be converted to heat energy on the surface of the material, so that the temperature of the friction surface will rise rapidly, and then the yield strength of the metal surface of the material matrix and dual will decrease. Eventually cause the engagement to weaken and the friction coefficient is decreases. As shown in Fig. 4, the friction coefficient also has a higher value when $600 \mathrm{r} / \mathrm{min}$. The friction coefficients are $0.4,0.42,0.44$ and 0.48 under $50 \mathrm{~N}, 75 \mathrm{~N}, 100 \mathrm{~N}$ and $150 \mathrm{~N}$. They meet the requirements of friction brake materials $[10,11]$.
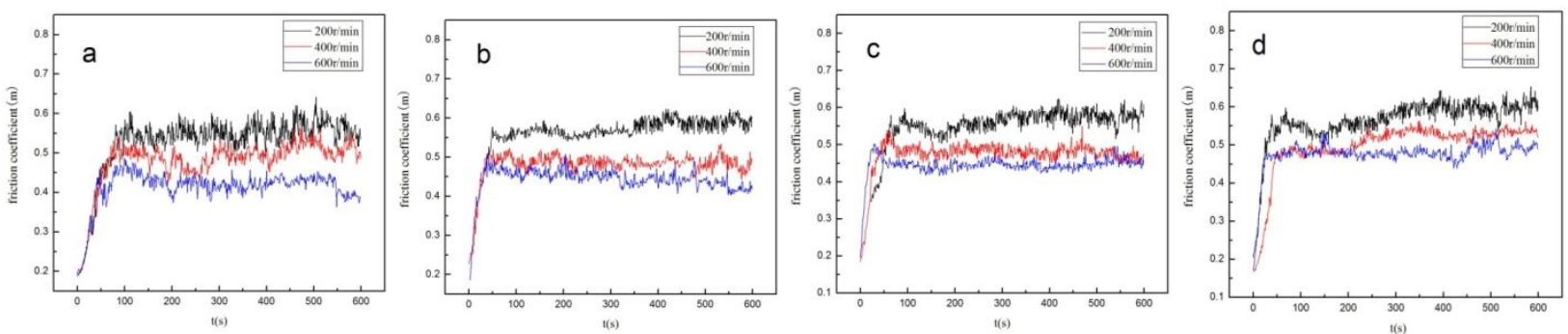

Fig. 4 The curves of friction coefficient under different loads (a) $50 \mathrm{~N}$; (b) $75 \mathrm{~N}$; (c) $100 \mathrm{~N}$; (d)150N

\subsection{Effect of friction speed on wear rate.}

Fig. 5 shows the wear rate curves of the material under different loads. The wear rate increases with the increase of friction speed. The friction heat increases with the friction speed increases during the frictional process. The friction heat makes the material matrix soften and the strength of the material decreases so that the wear of the material increases with the speed increases. Under the loading of $50 \mathrm{~N}, 75 \mathrm{~N}$ and $100 \mathrm{~N}$, the wear rate increased slowly. While the load is $150 \mathrm{~N}$, it showed a rapid growth. The material will quickly pass the run-in period because of high speed and high load condition. Although the friction coefficient decreases right now, the anti-fatigue resistance of the material decreases, so that the wear rate will increase rapidly. The samples also have a low wear rate at high speed is due to the friction heat to promote the formation of friction surface carbon lubricating film during the friction process. The lubricating film reduces the direct contact area between the friction material and the friction pair. Therefore, the wear rate of the material is lower and the abrasion resistance of the material is improved [12].

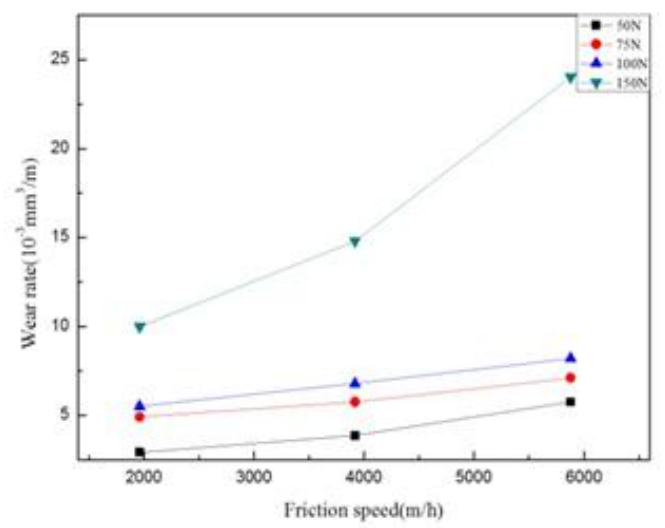

Fig. 5 Wear rate at different loads

\subsection{Wear mechanism analysis.}

In order to further study the friction and wear mechanisms of the experimental materials, the surface of the sample was observed and analyzed by SEM. Fig. 6 shows that the wear micromorphology in the friction surface at $100 \mathrm{~N}$ load under the different friction speeds. When the friction speed is $200 \mathrm{r} / \mathrm{min}$, the static load characteristic of the friction force is advantageous to the $\mathrm{SiO}_{2}, \mathrm{Cr}$ and other particles of the plowing effect under the certain load. The plowing of hard points with high 
hardness and high roughness makes the friction surface appear shallower ploughing, such as $\mathrm{SiO}_{2}$ and $\mathrm{Cr}$ particles. At the same time, the friction surface forms a friction film that has lubrication. Under the condition of $400 \mathrm{r} / \mathrm{min}$, the plowing of $\mathrm{SiO}_{2}$ and $\mathrm{Cr}$ particles destroyed the lubricating film on the friction surface, so the local of the lubricating film on the friction surface appears the phenomenon of damage. Under high friction speed of $600 \mathrm{r} / \mathrm{min}$, friction heat produced in the friction process causes the temperature of friction surface to rise. High temperature softening leads to the matrix strength to reduce, exacerbating the material wear. $\mathrm{SiO}_{2}, \mathrm{Cr}$ and other particles are broken under the strong impact of friction force, and embedded in the high temperature softening matrix to reduce the role of ploughing and the mechanical meshing force. At the same time, the lubricating film on the friction surface is peeling off, the material is directly contacted with the friction pair, so the friction coefficient is reduced [13]. The friction surface topography of the material shows that the abrasive wear occurs during the friction process.

During the wear process, the occurrence of oxidation wear is inevitable. The main reason is that a large number of deformation occurs on the friction surface. Serious distortion causes the surface energy to rise and the atomic activity is large. With the influence of the friction heat, the friction surface is in a state of instability, which is easy to react with the oxygen in the atmosphere to form a layer of oxide film. The properties of the oxide film, such as hardness, thickness, composition of the film, the bonding strength with matrix and so on. They have a strong influence on the friction and wear of materials. If the thin and compact surface film is formed and the combination of membrane and matrix is firm. Then the friction coefficient will be greatly reduced. If the formation of the surface film is too thick, the surface of the film will form a high stress and deformation and the oxide film will also produce cracks or peel off. Thus, the oxidation wear is formed.

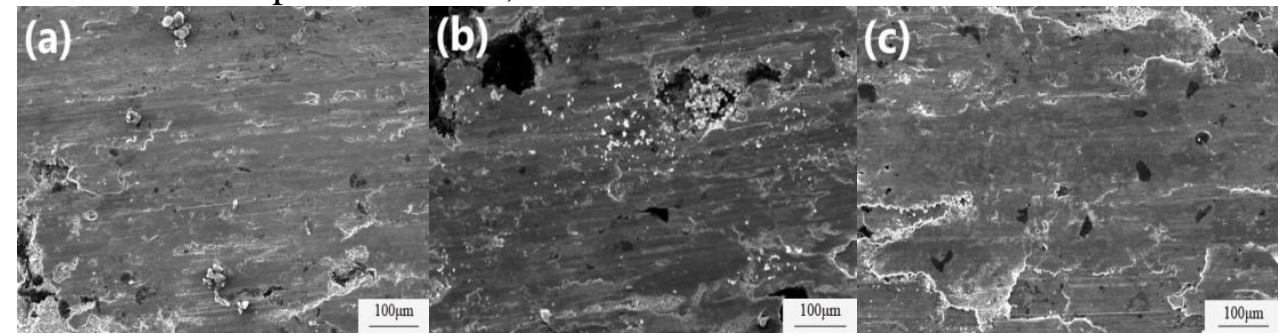

Fig. 6 Surface topography after friction under 100N load (a)200r/min; (b)400r/min; (c)600r/min

\section{Conclusion}

The $\mathrm{Cu}$-based friction material was prepared by the larger natural flake graphite $(150 \sim 250 \mu \mathrm{m})$ and smaller iron particles $(\leq 70 \mu \mathrm{m})$ by cold pressing and sintering process. The relative density is $75.4 \%$, the hardness is $119 \mathrm{HRB}$ and the compressive strength is $78.77 \mathrm{MPa}$.

$\mathrm{Cu}$-based friction material containing larger natural flake graphite and smaller Fe particles has good friction wear performance. The friction coefficient decreases with the increase of friction speed and the decrease of the load. When the sliding speed varying from 200 to 600r/min under the load of $150 \mathrm{~N}$, the friction coefficient is about $0.5 \sim 0.62$. And when the load varying from $50 \mathrm{~N}$ to $150 \mathrm{~N}$ at the speed of $600 \mathrm{r} / \mathrm{min}$, the friction coefficient is about 0.4 0.48. The friction coefficient varies little and is very stable.

The wear rate increases with the increase of load and speed. And the main wear mechanisms are abrasive wear and oxidation wear.

\section{Acknowledgements}

This work is financially supported by the Special Foundation for Industry Innovation of Jilin Province (No.2017C047-4). 


\section{References}

[1] M. Gao, Y. Chen, Y. Z. Zhang. Research Status and Prospect of High-speed Railway Brake Profile [J].Hot Working Technology. Vol. 39 (2010) No. 24, p. 113-115.

[2]K. Y. Dai. Research Status and Development of High-speed Train Friction Braking Material[J]. Locomotive \& Rolling Stock. Technology. Vol. 12 (1994) No. 2, p. 1-8.

[3]J. C. Zhou, B. Y. Huang. Progress in the Research of Train-Brake Friction Material[J]. Journal of Materials Science and Engineering. Vol. 17 (1999) No. 2, p. 91-93.

[4]H. X. Gao, J. X. Liu, R. M. Zhu. Study on Friction Wear Property of Train Brake Materials by Copper-based Power Metallurgy[J]. Journal of Materials Science and Engineering. Vol. 23 (2005) No. 6, p. 871-874.

[5]P. P. Yao, S. P. Li, X. Xiong. Comparison on the Friction and Wear Behavior of Fe and SiO2 in Cu-based Friction-Materials[J]. Hunan Nonferrous Metals. Vol. 19 (2003) No. 5, p. 31-35.

[6]H. J. Xu, X. Xiong, D. Y. Ji, et al. Effect of braking speed on friction properties of c/c composite braking pad[J]. Tribology. Vol. 21 (2001) No. 6, p. 443-447.

[7] R. Holinski, D. Hesse. Changes at interfaces of friction components during braking[J]. Proceedings of the Institution of Mechanical Engineers Part D Journal of Automobile Engineering. Vol. 217 (2003) No. 9, p. 765-770.

[8]X. M. Han, F. Gao, B. Y. Song, et al. Effect of Friction Speed on Friction and Wear Performance of Cu-matrix Friction Materials[J]. Tribology. Vol. 29 (2009) No. 1, p. 89-96.

[9]D. Han. Study on Preparation of Copper-based Friction Braking Materials and Friction and Wear Properties[D]. Changchun University of Technology, 2015. p. 1-2

[10]X. K. Du, Z. L. Shi, M. H. Ye, et al. Friction and Wear Behavior of Fe-based Sintered Lining Material for Highway Train[J]. Tribology. Vol. 21 (2001) No. 4, p. 256-259.

[11]K. Yang. Powder metallurgy fabricated $\mathrm{Cu}-\mathrm{Fe}$ based braking materials for high speed trains[D]. Northeastern University, 2011. p. 17-18.

[12]W. G. Chen, Q. W. Luo, J. Zhang, et al. Study of Fe and Cu-based P/M friction materials for automotive brake pads[J]. Powder Metallurgy Technology. Vol. 30 (2012) No. 3, p. 192-199.

[13] A. M. Kovalchenko, O. I. Fushchich, S. Danyluk. The tribological properties and mechanism of wear of $\mathrm{Cu}$-based sintered power materials containing molybdenum disulfide and molybdenum diselenite under unlubricated sliding against copper[J]. Wear. Vol. 290 (2012) No. 7, p. 106-123. 